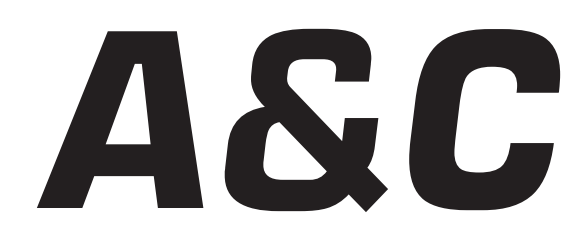

Revista de Direito Administrativo \& Constitucional

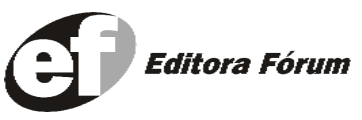

A\&C R. de Dir. Administrativo e Constitucional, Belo Horizonte, ano 6, n. 23, p. 1-253, jan./mar. 2006 


\section{A\&C REVISTA DE DIREITO ADMINISTRATIVO E CONSTITUCIONAL}

\section{IPDA}

Instituto Paranaense

de Direito Administrativo

Direção Geral

Romeu Felipe Bacellar Filho

Direção Editorial

Paulo Roberto Ferreira Motta

Direção Executiva

Emerson Gabardo

Conselho de Redação

Edgar Chiuratto Guimarães

Adriana da Costa Ricardo Schier

Célio Heitor Guimarães

Conselho Editorial

Adilson Abreu Dallari

Alice Gonzáles Borges

Carlos Ari Sundfeld

Carlos Ayres Britto

Carlos Delpiazzo

Cármen Lúcia Antunes Rocha

Celso Antônio Bandeira de Mello

Clèmerson Merlin Clève

Clóvis Beznos

Enrique Silva Cimma

Eros Roberto Grau

Fabrício Motta

Guilhermo Andrés Muñoz (in memoriam)

Jaime Rodríguez-Arana Muñoz

Jorge Luís Salomoni
José Carlos Abraão
José Eduardo Martins Cardoso

José Luís Said

José Mario Serrate Paz

Juan Pablo Cajarville Peruffo

Juarez Freitas

Julio Rodolfo Comadira

Luís Enrique Chase Plate

Lúcia Valle Figueiredo

Manoel de Oliveira Franco Sobrinho

(in memoriam)

Marçal Justen Filho

Marcelo Figueiredo

Márcio Cammarosano

Maria Cristina Cesar de Oliveira
Nelson Figueiredo

Odilon Borges Junior

Pascual Caiella

Paulo Eduardo Garrido Modesto

Paulo Henrique Blasi

Paulo Neves de Carvalho (in memoriam)

Paulo Ricardo Schier

Pedro Paulo de Almeida Dutra

Regina Maria Macedo Nery Ferrari

Rogério Gesta Leal

Rolando Pantoja Bauzá

Sérgio Ferraz

Valmir Pontes Filho

Yara Stropa

Weida Zancaner

\footnotetext{
A246 A\&C Revista de Direito Administrativo e Constitucional. ano 3, n. 11, jan./mar. 2003. Belo Horizonte: Fórum, 2003.

Trimestral

ano 1, n.1, 1999 até ano 2, n.10, 2002 publicada pela Editora Juruá em Curitiba

ISSN: 1516-3210

1. Direito Administrativo. 2. Direito Constitucional. I. Fórum.
}

CDD: 342 CDU: 33.342

(c) Editora Fórum Ltda. 2006

Todos os direitos reservados. É proibida a reprodução total ou parcial, de qualquer forma ou por qualquer meio eletrônico ou mecânico, inclusive através de processos xerográficos, de fotocópias ou de gravação, sem permissão por escrito do possuidor dos direitos de cópias (Lei $n^{\circ}$ 9.610, de 19.02.1998).

Editora Fórum Ltda

Av. Afonso Pena, 2770 - 15\%16ªndar - Funcionários

CEP 30130-007 - Belo Horizonte/MG - Brasil

Tel.: 08007043737

Internet: www.editoraforum.com.br

e-mail: editoraforum@editoraforum.com.br
Editor responsável: Luís Cláudio Rodrigues Ferreira Projeto gráfico e diagramação: Luis Alberto Pimenta Revisora: Olga M. A. Sousa

Pesquisa jurídica: Fátima Ribeiro - OAB/MG 74868

Bibliotecária: Nilcéia Lage de Medeiros

CRB 1545/MG 6a região

Os conceitos e opiniões expressas nos trabalhos assinados são de responsabilidade exclusiva de seus autores.

Impressa no Brasil / Printed in Brazil

Distribuída em todo Território Nacional 


\title{
A evolução da Administração Pública e de seus mecanismos de controle na Constituição Federal
}

\author{
Francisco Taveira Neto \\ Advogado. Vice-Presidente do Instituto de Direito Administrativo de Goiás - IDAG. Subchefe do \\ Gabinete de Controle Interno da Governadoria em Goiás
}

Sumário: Introdução - 1 A evolução da Administração Pública: legalidade e eficiência - 2 Controle da Administração nas constituições da República - 2.1 Tribunais de contas - 2.2 Do sistema de controle interno - 2.3 Controle social e suas fragilidades - 3 Considerações finais - Referências

Resumo: Evolução da Administração e dos mecanismos de controle no Texto Constitucional - Gestão e controle institucional com foco no resultado - Necessidade de obediência simultânea aos princípios da eficiência e da legalidade - Baixa participação popular - Necessidade de consciência política para o exercício do controle social.

Palavras-chave: Administração Pública, mecanismos de controle na Constituição Federal ; Administração Pública, evolução ; Administração Pública, legalidade ; Administração Pública, eficiência

\section{Introdução}

O que se pretende com este estudo é obter uma visão crítica de nosso sistema de controle da Administração Pública em face de tantas mudanças ocorridas no aparelho do Estado nos últimos tempos.

O desafio proposto é verificar se estas mudanças introduzidas por várias Emendas Constitucionais afetaram apenas o aparelho do Estado ou se estas alterações alcançaram também as instituições e os mecanismos de controle da Administração.

\section{A evolução da Administração Pública: legalidade e eficiência}

A evolução do modelo de Administração Pública tem sido objeto de estudo das mais variadas ciências sociais como é o caso da sociologia, da economia e do direito. Autores dos mais renomados têm se ocupado em escrever suas críticas acerca da evolução de uma Administração que parte do "patrimonialismo" - ocasião em que a fazenda pública e a fazenda do príncipe se confundiam —, passando pela administração burocrática — ocasião em que a expressão burocracia foi bastante deturpada —, pretendendo-se chegar ao modelo gerencial que tem como foco o resultado alcançado pela gestão. 
O que se vê nos dias atuais é uma crítica ferrenha ao modelo jurídicoformal vigente, que dita o agir do administrador público brasileiro. Para alguns, os indesejados resultados alcançados na gestão pública são decorrentes dos passos burocráticos excessivos previstos no ordenamento. Neste sentido, concluem que a é a "burocracia" o elemento que frustra os melhores resultados na gestão pública.

Sem embargo, o que precisamos reconhecer é que, nos moldes estabelecidos em nossa Carta Política, a Administração Pública brasileira é burocrática. Vale lembrar que é burocrática no verdadeiro sentido da palavra, nos moldes da teoria de Max Weber. ${ }^{1}$ São várias as regras constitucionais que evidenciam este caráter burocrático. Dentre elas, destacamse o dever de licitar para obras, serviços, compras e alienações, previsto no art. 37, XXI, além da necessidade de concurso público para o provimento em cargos e empregos públicos, ressalvados aqueles em comissão, prevista no inciso II do mesmo artigo.

Vale lembrar que o mesmo ordenamento que estabelece a necessidade de obediência ao regime jurídico-administrativo impõe o dever de eficiência à Administração. Aliás, para alguns autores, como Celso Antônio Bandeira de Mello, a razão de existir das organizações administrativas que compõem a estrutura do Estado é a eficiência. A previsão expressa do princípio da eficiência no caput do art. 37 da Constituição não alterou o dever de adotar a melhor conduta ao administrador público. Este princípio é, em verdade, "uma faceta de um princípio mais amplo já superiormente tratado, de há muito, no direito italiano: princípio da boa administração". ${ }^{2}$

A Emenda Constitucional $n^{\circ}$ 19, de 04.06.1998, ao inserir o princípio da eficiência no caput do art. 37 da Carta Política, não figura como "divisor de águas" entre uma Administração antes ineficiente, para a partir de sua promulgação, como em um toque de mágica, torná-la eficiente. Eficiência é dever perene da Administração. O que fez a alteração constitucional foi tornar a conseqüência lógica do sistema normativo manifesta em um dispositivo tão importante como é o art. 37, caput, como, de resto, também o fez o legislador constituinte originário em outros dispositivos da Constituição Federal. Há, no Brasil (talvez por um déficit cultural, uma vez que o costume aqui é desconhecer o teor da norma) a prática de fazer constar,

\footnotetext{
Para Max Weber a expressão burocracia significa o melhor procedimento para se alcançar um dado objetivo, ao contrário do sentido banalizado que a expressão ganhou nos tempos atuais.

2 MELLO, Celso Antônio Bandeira. Curso de Direito Administrativo.
}

A \& C R. de Dir. Administrativo e Constitucional, Belo Horizonte, ano 6, n. 23, p. 135-144, jan./mar. 2006 
no texto Constitucional, expressões óbvias, passíveis de dedução pelos povos menos aculturados, mas que aqui em nosso País ganham a importância de "texto constitucional".

Registre-se que a expressão eficiência já se encontrava encartada na Lei maior de nosso ordenamento, desde seu texto originário, no art. 74 que cuida das atribuições do sistema de controle interno da Administração, como a seguir se vê:

Art. 74. Os Poderes Legislativo, Executivo e Judiciário manterão, de forma integrada, sistema de controle interno com a finalidade de:

I - avaliar o cumprimento das metas previstas no plano plurianual, a execução dos programas de governo e dos orçamentos da União;

II - comprovar a legalidade e avaliar os resultados, quanto à eficácia e eficiência, da gestão orçamentária, financeira e patrimonial nos órgãos e entidades da administração federal, bem como da aplicação de recursos públicos por entidades de direito privado; (grifo nosso)

Da análise do dispositivo transcrito, apura-se como óbvio o dever de eficiência ao Administrador público de modo que o constituinte estabelece como competência do sistema de controle interno a avaliação dos resultados alcançados pela Administração tanto em relação à eficiência que se tem como a relação ótima entre o custo e o benefício da ação governamental, como em relação à eficácia que alcança a aferição quanto à produção de efeitos dessa ação perante sua destinatária que é a coletividade.

Como já foi dito, o que fez a Emenda Constitucional no $19 / 98$, ao inserir o princípio da eficiência no caput do art.37, foi apenas tornar a conseqüência lógica do sistema normativo manifesta em um dispositivo emblemático para a Administração.

Com efeito, ao administrador público incumbe os deveres de eficiência e, ao mesmo tempo, de obediência ao ordenamento. A República Federativa do Brasil constitui Estado de Direito, além de se apurar no texto de nossa Constituição Federal o princípio da legalidade como regra para a gestão pública. Nasce, daí, o desafio à Administração de conciliar, simultaneamente, obediência aos princípios da eficiência e da legalidade.

Ser eficiente sem obedecer ao ordenamento jurídico (regime jurídicoadministrativo) é flagrantemente inconstitucional. Fere de morte o princípio da legalidade. Não menos inconstitucional, porém, é atender ao ordenamento jurídico sem que a gestão pública produza efeito real. Desta 
vez, fere-se de morte o princípio da eficiência. Assim, não resta alternativa à Administração: há que ser eficiente e obediente à legalidade, ao mesmo tempo e por todo o tempo.

A quem o ordenamento constitucional incumbiu a nobre missão de se exercer o controle da Administração de modo a aferir se está havendo o fiel cumprimento dos princípios da legalidade e eficiência?

A Constituição Federal brasileira traz um plexo de mecanismos de controle que, ao final, formam o sistema de controle da Administração Pública que estudaremos a seguir.

\section{Controle da Administração nas constituições da República}

A expressão controle significa a "fiscalização exercida sobre as atividades de pessoas, órgãos, departamentos, ou sobre produtos, etc., para que tais atividades, ou produtos, não se desviem das normas preestabelecidas". ${ }^{3}$ Esta fiscalização significa, em verdade, um processo de diminuição de poder. Trata-se do chamado sistema de freios e contrapesos (checks and balances) em que um poder (instituição) limita a atuação de outro.

A Administração Pública no Brasil está sujeita a diferenciados mecanismos de controle. Reservando Seção específica, a Constituição Federal de 1988 dispõe nos arts. 70 a 74 sobre a fiscalização contábil, financeira e orçamentária. Tratam-se dos controles externo e interno, exercidos pelas Casas Legislativas, pelos Tribunais de Contas e pelo sistema de controle interno de cada Poder.

Demais disso, há o poder-dever do Ministério Público, na condição de fiscal da lei, de exercer o controle dos atos da administração, além, é claro, do sistema de jurisdição final única, consagrado no ordenamento brasileiro, que atribui ao Poder Judiciário decidir, em última instância, sobre qualquer controvérsia em que figure, ou não, o poder púbico como uma das partes.

Não obstante a toda esta plêiade de instrumentos de controle institucionais, há que se considerar com o devido reconhecimento a nobre missão a ser exercida pelo controle social. É a coletividade a maior legitimada para acompanhar a gestão dos bens e recursos que são seus. Afinal, nos termos do parágrafo único do art. $1^{\circ}$ de nossa Magna Carta, "todo poder emana do povo que o exerce por meio de representantes eleitos, ou diretamente, nos termos desta Constituição".

${ }^{3}$ NOVO Dicionário Eletrônico Aurélio versão 5.0 - Aurélio Buarque de Holanda Ferreira.

A \& C R. de Dir. Administrativo e Constitucional, Belo Horizonte, ano 6, n. 23, p. 135-144, jan./mar. 2006 


\subsection{Tribunais de contas}

Tendo inspiração no Tribunal português congênere, cujas instituições embrionárias foram o Conselho da Fazenda e o Erário Régio, o Tribunal de Contas aparece, no Brasil, com a edição da Carta Constitucional Republicana de 24 de fevereiro de 1891 que anunciava dentro do Título V "Disposições Gerais" sua instituição por seu art. 89. Sua instalação, entretanto, só se deu em novembro de 1893.

A Carta de 1934 manteve o Tribunal de Contas conferindo-lhe mais destaque que a Constituição anterior, de modo que a ele reservou uma seção específica, a II Seção do Capítulo VI - Dos Órgãos de Cooperação nas Atividades Governamentais, do Título I que cuidara Da Organização Federal, além de alargar seu assento constitucional e instituir o controle prévio por parte da Corte de Contas como condição de validade dos atos administrativos.

A Constituição Federal de 1937, decretada pelo Presidente da República, dá um passo à trás, uma vez que cuida de várias instituições do Estado, dentre elas o Tribunal de Contas, de maneira bastante simplória, às vezes em um único artigo, deixando que toda regulamentação fosse objeto de Lei.

A promulgada Constituição de 1946 resgata uma melhor disposição quanto às instituições do Estado conferindo ao Tribunal de Contas, na Seção que cuida Do Orçamento atribuições próprias reconhecendo-lhe o poder de veto em determinadas despesas públicas quando autorizado por Lei o controle prévio de determinados atos.

Pela primeira vez, e desde então, a instituição Tribunal de Contas é tratada, no texto constitucional, dentro do Capítulo que cuida Do Poder Legislativo.

A decretada e promulgada Constituição de 1967 inaugura a abordagem do tema controle externo da Administração, atribuindo o seu exercício ao Congresso Nacional com o auxílio do Tribunal de Contas. Além disso, estabelece critérios para a sustação de atos o contratos administrativos e consagra a necessidade de sua apreciação quanto a legalidade de determinados atos.

Nossa Constituição atual cuidou de alargar o assento constitucional do Tribunal de Contas, cujas nobres missões já não eram pequenas, atribuindo-lhe ferramenta de controle de resultado da gestão pública. É o que se apura de uma leitura minuciosa do inciso IV do art. 71 que estabelece as competências do Tribunal de Contas da União como a seguir se vê:

A \& C R. de Dir. Administrativo e Constitucional, Belo Horizonte, ano 6, n. 23, p. 135-144, jan./mar. 2006 
IV - realizar, por iniciativa própria, da Câmara dos Deputados, do Senado Federal, de Comissão técnica ou de inquérito, inspeções e auditorias de natureza contábil, financeira, orçamentária, operacional e patrimonial, nas unidades administrativas dos Poderes Legislativo, Executivo e Judiciário, e demais entidades referidas no inciso II; (grifo nosso)

Está aí entregue aos Tribunais de Contas a ferramenta que lhes permite evoluir no exercício de suas atividades de um controle meramente legal, pautado na formalidade dos atos, para alcançar o controle do resultado da gestão pública.

A tão falada transição de uma administração burocrática para uma administração que se pretende gerencial ${ }^{4}$ é verificada até mesmo nas instituições de controle, dada a lucidez do constituinte de oferecer-lhes ferramenta permitindo a aferição dos efeitos sociais da atuação administrativa. É o controle gerencial posto à disposição dos Tribunais de Contas.

Os demais dispositivos que estabelecem as competências constitucionais das Cortes de Contas têm como signo maior o controle de legalidade dos atos e contratos administrativos, ao contrário do que se verifica das atribuições constitucionais do sistema de controle interno que veremos no tópico a seguir deste estudo.

Tem-se, portanto, nas competências constitucionais das Cortes de Contas vários dispositivos que dão relevo maior ao controle formal dos atos administrativos, sendo-lhes atribuída, também uma ferramenta de controle gerencial, via das auditorias de natureza operacional.

\subsection{Do sistema de controle interno}

A primeira menção do texto constitucional feita ao controle interno da Administração consta do art.72 da Constituição de 24 de janeiro de 1967. A idéia de se exercer controle dentro do próprio seio da Administração, ou controle interno, como se vê, só veio ganhar berço constitucional em tempos mais recentes.

Acompanhando a idéia de controle interno ou autocontrole, pudemos notar uma considerável evolução doutrinária no que tange à teoria do desfazimento dos atos administrativos. Institutos como a revogação

\footnotetext{
4 Registre-se aqui nosso entendimento de que a administração pública brasileira é burocrática, no verdadeiro sentido proposto pela teoria de Max Weber, reconhecendo-se, também, a possibilidade de se ampliar o foco do exercício do controle burocrático, até então interpretado erroneamente como controle meramente formal, para alcançar também o desejado controle de resultado, sem que para tanto tenhamos que abandonar a verdadeira burocracia. Ao contrário, se adotarmos um sistema genuinamente gerencial, em que só há preocupação com o resultado da gestão, deixando-se de verificar como andou o administrador no exercício de suas funções quanto à obediência ao regime jurídico-administrativo, estaríamos diante do abandono por parte das instituições de controle do seu constitucional dever de controle da legalidade.
} 
e a convalidação, antes vistos com larga reserva por uma considerável parcela dos administrativistas, ganharam maior aceitação chegando constar de textos normativos de grande relevância como a Lei $\mathrm{n}^{\circ} 9.784$ de 21 de janeiro de 1999 que regula o processo administrativo, no âmbito da União, e que constitui valioso instrumento colocado à disposição do administrador eficiente.

Impõe registro o fato de que a Constituição de 1967, muito antes de se falar em reforma do aparelho do Estado para o alcance de melhores resultados, já trazia no inciso II do art. 72 a manifesta preocupação "avaliar os resultados alcançados pelos administradores e verificar a execução dos contratos". A tão propalada preocupação com o resultado da gestão já constava do texto constitucional de 1967.

O constituinte de 1988 alarga este assento entregando expressamente aos órgãos de controle interno, ainda no texto originário da Carta Política, a nobre competência de controlar a obediência aos princípios da eficiência e da legalidade, conforme se apura da leitura do inciso II do art. 74 , já transcrito neste ensaio.

Da leitura dos demais incisos deste mesmo artigo encontramos expressões como "avaliar o cumprimento de metas"; a "execução dos programas de governo"; "avaliar os resultados, quanto a eficácia e eficiência" que dão maior ênfase ao controle de resultado, preocupando-se menos com o controle jurídico-formal, reservando-lhe apenas a parte em que menciona "comprovar a legalidade".

Esta modalidade de controle - de eficiência - proporciona, até, o controle pela omissão do gestor público. Como já foi mencionada, a razão de existir de qualquer órgão ou entidade na Administração é ser eficiente. $\mathrm{O}$ gestor acomodado, que não produz efeito real no exercício de sua função, merece ser repreendido. Não basta "não fazer errado". É preciso "fazer certo".

Registre-se, ainda, que os sistemas de controle interno dos poderes constituídos têm ganhado um maior reconhecimento de sua importância, sendo-lhes conferido na maior parte das pessoas políticas que integram a República Federativa do Brasil o status de órgão autônomo e independente, a exemplo do que ocorreu na União que instituiu sua Controladoria Geral, além de vários Estados que assim também o fizeram.

\subsection{Controle social e suas fragilidades}

A Constituição Imperial de 1824 já trazia em seu art. 157 a hipótese de se exercer o controle social por meio da ação popular. Dizia o dispositivo: "Art. 157. Por suborno, peita, peculato, e concussão haverá contra elles A \& C R. de Dir. Administrativo e Constitucional, Belo Horizonte, ano 6, n. 23, p. 135-144, jan./mar. 2006 
acção popular, que poderá ser intentada dentro de anno, e dia pelo proprio queixoso, ou por qualquer do Povo, guardada a ordem do Processo estabelecida na Lei” (grifo nosso).

As Cartas Constitucionais de 1891, de 1934, de 1937 e 1946, foram silentes quanto ao instituto da ação popular até a edição da Constituição de 1967 que voltou a assegurar este importante mecanismo para o exercício do controle social.

A Constituição de 1988, chamada "Constituição Cidadã", trouxe um considerável plexo de instrumentos que permite à sociedade o exercício do controle quanto a gestão pública. Dentre estes instrumentos merecem registro a ação popular prevista no art. $5^{\circ}$, inciso LXXIII, a possibilidade das comissões do Congresso Nacional realizarem audiências públicas com entidades da sociedade civil, conforme prevê o art. $58, \S 2^{\circ}$, inciso II, a participação popular na formulação de políticas de assistência social prevista no art. 204, II, dentre outros dispositivos que guardam relação com o controle pela coletividade.

De outro lado, na inversa direção que se apura da evolução do texto constitucional no tocante ao controle social, verifica-se, na prática, o total desinteresse da população em acompanhar e controlar a gestão pública no Brasil.

São bastante esclarecedores os comentários trazidos por Jorge Ulisses Jacoby Fernandes em sua obra Tribunais de Contas do Brasil-Jurisdição e Competência, na parte em que faz uma importante abordagem sobre o controle social, esclarecedora de sua (in)eficácia.

O controle social é tido nas ciências da política e da filosofia como o mais eficaz dos mecanismos de controle, uma vez que seu conceito considera todos os integrantes da sociedade. Esta idéia não pode ser, de chofre, contestada, embora saibamos que na prática, notadamente nos dias atuais, o que prepondera é o descontrole, com raras exceções.

Com efeito, procuremos compreender a razão pela qual esta notável assertiva científica se traduza, talvez, no mais ineficaz mecanismo de controle.

O controle social divide-se em interno e externo.

O controle social interno consiste na preparação do indivíduo para o exercício de sua cidadania. É o nível de sua instrução. É a qualidade da informação que recebe em casa, na escola, pela mídia.

Enfim, como o próprio nome diz, é a preparação interna do indi-

A \& C R. de Dir. Administrativo e Constitucional, Belo Horizonte, ano 6, n. 23, p. 135-144, jan./mar. 2006 
víduo que antecede o fiel exercício do controle social propriamente dito (externo).

O controle social externo, por outro lado, é a adoção e emprego de medidas que visem assegurar a participação popular. Constituem o alvo, para o exercício deste controle, as condutas que não guardam harmonia com os valores sociais de um povo.

Nota-se, daí, que o exercício do controle social depende basicamente do nível de consciência cidadã de um povo.

A falência do ensino público em nosso país, a manipulação do conhecimento pela elite dominante, ao lado da ampla divulgação da degradação dos valores culturais, que diuturnamente bombardeia a instituição familiar, são fatores que indubitavelmente colaboram no despreparo do cidadão brasileiro para o exercício do controle social.

A base de nossa pirâmide social não é capaz de se organizar, de exigir a quem de direito as respostas aos seus anseios, embora seja legítima para tanto. O que nos falta é o controle social interno.

\section{Considerações finais}

Ao lado da evolução conferida pelos textos constitucionais à Administração Pública de modo a torná-la mais ágil e com menor apego jurídicoformal, verificou-se também a evolução dos mecanismos e das instituições de controle promovida pela própria Constituição Federal. Há que se controlar forma e resultado, legalidade e eficiência, impondo às instituições controladoras que atuem em prol da Administração e não contra ela. Há que se conciliar legalidade e eficiência quer na Administração propriamente dita, quer no exercício de seu controle;

Aos Tribunais de Contas e ao Sistema de Controle Interno foram entregues pela Carta Magna atribuições que impõem controle a ser exercido quanto à legalidade, bem como quanto ao resultado alcançado pela gestão. Aos Tribunais foram várias as competências de controle formal, sendo-lhes garantido o controle dito gerencial pelas auditorias operacionais. Ao Sistema de Controle Interno o Constituinte sublinhou maior importância ao controle gerencial, impondo-lhe o dever de comprovação da legalidade dos atos de gestão. Forçoso concluir que à luz da Carta de 1988 deverão as instituições de controle interno e externo, atendendo ao constitucional princípio da eficiência, uma vez que são instituições públicas, exercer controle tanto jurídico-burocrático, quanto com o foco no resultado da gestão;

A eficácia do controle social depende de dois requisitos básicos: a

A \& C R. de Dir. Administrativo e Constitucional, Belo Horizonte, ano 6, n. 23, p. 135-144, jan./mar. 2006 
preparação cultural da população para o fiel exercício deste, o que devemos ter como meta se quisermos sonhar com a justiça social em nosso país e o engajamento dessa população para impor mudanças na sociedade brasileira.

\section{Referências}

ATALIBA, Geraldo. República e Constituição. 2. ed. São Paulo: Malheiros, 2001.

BANDEIRA DE MELlo, Celso António. Curso de Direito Administrativo. 18. ed. São Paulo: Malheiros, 2003.

CIRNE LIMA, Ruy. Princípios do Direito Administrativo. 6. ed. São Paulo: Revista dos Tribunais, 1987.

DI PIETRO, Maria Sylvia Zanella. Direito Administrativo. 13. ed. São Paulo: Atlas, 2001.

FERNANDES, Jorge Ulisses Jacoby. Tribunais de Contas do Brasil: Jurisdição e Competência. Belo Horizonte: Fórum, 2003.

FERrAZ, Luciano de Araújo. Controle da Administração Pública. Belo Horizonte: Mandamentos, 1.999.

FREITAS, Juarez. O Controle dos Atos Administrativos e os Princípios Fundamentais. 2. ed. São Paulo: Malheiros, 1999

SUNDFELD, Carlos Ari. Fundamentos de Direito Público. 4. ed. São Paulo: Malheiros, 2003.

Informação bibliográfica deste texto, conforme a NBR 6023:2002 da Associação Brasileira de Normas Técnicas (ABNT):

TAVEIRA NETO, Francisco. A evolução da Administração Pública e de seus mecanismos de controle na Constituição Federal. A\&C Revista de Direito Administrativo e Constitucional, Belo Horizonte, ano 6, n. 23, p. 135-144, jan./mar. 2006 